\title{
Recognition of Teachers about Pupils' Competencies to Use Social Network System
}

\author{
Masami Yoshida
}

\begin{abstract}
We investigate the opinions of Japanese primary school teachers in terms of their perceptions of their pupils' competencies regarding media information literacy at using social network services (SNS). Valid criteria to evaluate competencies were recently advocated by the United Nations Educational, Scientific, and Cultural Organization, and 25 performance criteria items in three competence categories were selected for this study. In particular, participation competence of the middle level was used to measure the weight of teachers' opinions of importance, and we introduced paired comparisons and the geometric mean method to calculate importance. As a result, communication competence was evaluated as being somewhat active, and monitoring competence was evaluated as being somewhat inactive. In addition, counter risk ability was recognized as the most important performance criterion item in participation competence. Based on a discussion, we reveal the need to develop greater competence to expand connection of users in SNS.
\end{abstract}

Index Terms-Media information literacy, primary school, pupils' competencies, social network service, UNESCO.

\section{INTRODUCTION}

According to the report of Ministry of Internal Affairs and Communication in Japan, the dissemination of Internet was reported as follows [1].

Access to high-speed broadband internet has spread to 97.3\% of houses. And, the number of mobile terminal subscriptions has reached 136 million, which exceeds the population of Japan. The cost of network connection has also drastically decreased, especially communication cost of mobile terminals are downed to $18 \%$ of 1995 . As a result, all pupils have able to access the Internet in their daily lives.

Additionally, the broadband Internet penetration rate in

Japanese schools is $100 \%$ [2].

Owing to the wide availability of affordable information devices and the variety of connectivity networks, pupils are changing their approach to using the Internet. Social network systems (SNS) such as Facebook and Twitter have demonstrated their potential to involve pupils in wired communities and simultaneously change the role of teachers [3]. According to a governmental survey, $30.3 \%$ of primary school pupils in Japan had their own smartphones in 2013. In particular, the smartphone ownership ratio of pupils increased in lower grade (i.e., $41.4 \%$ in 4 th grade and $35.7 \%$ in 6 th grade) [4]. Another survey conducted in 2015 reported that

Manuscript received June 20, 2016; revised August 31, 2016. This work was supported in part by the research project Grant-in-Aid for scientific research (B) of JSPS, project number 26301035.

M. Yoshida is with the Faculty of Education, Chiba University, Chiba, Japan (e-mail: yoshida-m@faculty.chiba-u.jp).
$58.2 \%$ of 6th grade pupils used a smartphone for communication in their home [5].

Based on results of the "Young method" [6] to evaluate the level of Internet addiction disorder, primary-grade pupils are less addicted to the Internet than adults. Nevertheless, various problems had been reported regarding use of SNS by youth, such as communication troubles in SNS, the rapid increase in the number of pupils who are drawn into child prostitution or obscene material distribution, and the leakage of personal information on SNS [7].

In fact, $50 \%$ of primary schools have reported cases of pupils' communication troubles on SNS [8].

Meanwhile, recent studies on Media Information Literacy (MIL) advocate competencies in social media use to adapt to the new information and communication technology (ICT) society. The related investigation was conducted by the United Nations Educational, Scientific, and Cultural Organization (UNESCO), which proposed an assessment framework to value competencies to use ICT [9].

The purpose of this study is to investigate the opinions of Japanese elementary school teachers in terms of their recognition of pupils' competencies to use SNS. We employed a questionnaire method, and the items were developed referring to the UNESCO criteria.

\section{Performance Criteria of SNS Competencies}

The MIL assessment framework includes the MIL competency matrix to assess competencies. This matrix consists of the following elements:

- MIL components (3): Three overarching categories, namely Access, Evaluation, and Creation.

- MIL subject matters (12): Each subject matter explains activities to use a corresponding competence. Each MIL component consists of four middle-ranking classifications. For example, within Creation, there are Creation, Communication, Participation, and Monitoring .

- Competencies (12): Paired with MIL subject matters to explain a person with competencies.

- Performance criteria (113): Details of the competence criteria.

- Levels of proficiency (3): Three levels of mastering MIL components: Basic, Intermediate, and Advanced.

This framework involves a wide range of ICT competencies. We selected the "creation" MIL component (italicize above) and three MIL subject matters and competencies (italicize above) as the target area of this investigation based on a report of pupils in a previous study [10].

The following statements explain 25 selected performance 
criteria items. Fig. 1 shows the profile of a selected part in the UNESCO framework and a number of frameworks of this study divided by a number of full frameworks of UNESCO in parentheses. In the following statements, "media" in competencies and performance criteria were modified to SNS.

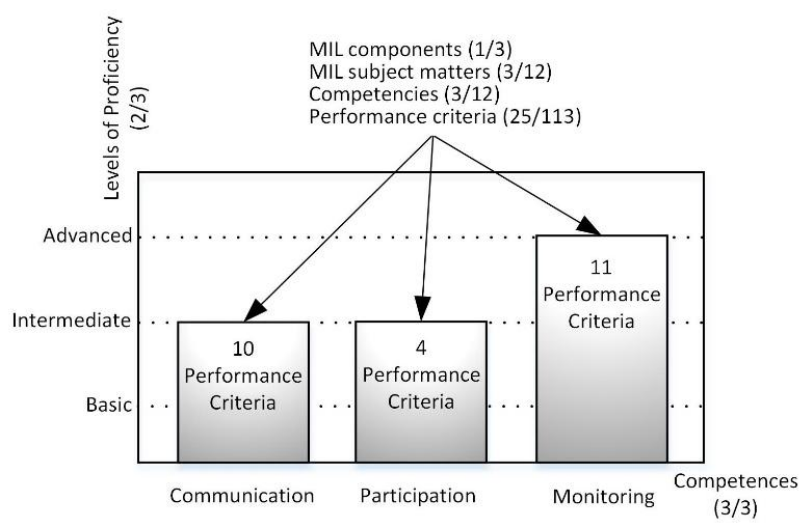

Fig. 1. Profile of the MIL component.

\section{Communication competence}

MIL competence: Communicate information, media content, and knowledge in an ethical, legal, and effective manner using SNS.

1) Knows that new knowledge should be shared, distributed, and communicated in SNS

2) Chooses the data format that best supports the communication, distribution, and sharing of data and knowledge, taking into account the data size and type of users

3) Uses various online tools for the purpose of communicating, distributing, and sharing data and knowledge

4) Identifies, copies, communicates, distributes, and shares information, data, and knowledge in contextually relevant settings to SNS users

5) Communicates data and messages in an ethical way

6) Communicates data and messages in a legal way

7) Knows how to protect privacy and intellectual rights

8) Is aware of the consequences and risks of communicating, distributing, and sharing knowledge on SNS

9) Understands the interdependencies between users and victims/perpetrators/bystanders/witnesses on SNS

10) Shares data and knowledge through various SNS

Participation competence (Italicize keywords are used as initials of items in the result section.)

MIL competence: Engaged with SNS for self-expression, intercultural dialogue, and democratic participation via various means in an ethical, effective, and efficient manner.

- Recognizes the importance of being engaged and involved in SNS

- Aware of the consequences and risks of participating in SNS

- Shares and interacts with users of SNS, physically or online

- Engages and participates in SNS activities through various online tools

\section{Monitoring competence}

MIL Competence: Monitoring the impact of created and distributed information, SNS content, and knowledge and the use existing media and other information providers.

1) Knows about the need and importance of monitoring SNS for shared data and knowledge

2) Uses or establishes monitoring method and skills for periodical assessment of the effectiveness of intended impacts

3) Monitors and makes judgments on shared data and knowledge, such as quality, impact, and integrity of practices

4) Identifies and analyses how SNS users respond to data and knowledge and impact

5) Knows and uses available SNS monitoring services and tools

6) Knows how the results of monitoring could be used to improve or create new data and knowledge

7) Knows how to monitor SNS ownership and its implications

8) Understands the functions and role of institutions providing public relations services and how institutions influence users and decision making

9) Monitors the functions of public relations services and lobbyists

10) If required, redirects and recasts data and messages based on the comparison of actual results with intended results

11) Knows how and where to communicate appreciation or complaints

\section{METHOD}

\section{A. Questionnaire}

We used the following three questionnaires consisting of two styles to collect the opinions of the teachers. The image of the styles is shown in Fig. 2, which shows a questionnaire of communication competence, a questionnaire of participation competence, and a questionnaire of monitoring competence from left to right.
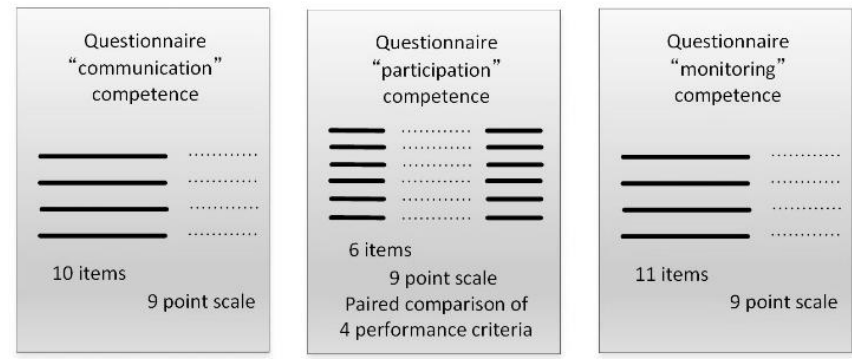

Fig. 2. Three questionnaires.

Communication competence and monitoring competence questionnaires

We used questionnaires with nine-point scales. Ten items (C1-C10) for communication competence and 11 items (M1-M11) for monitoring competence were arranged from the corresponding performance criteria items, and we asked the teachers for their opinions of their pupils' abilities for each of the performance criteria items.

We scaled the data by the intensity proposed by Saaty [11] (Table I). We used the geometric mean to calculate the scores. 
TABLE I: INTENSITY OF ITEMS

\begin{tabular}{cc}
\hline \hline Intensity & Definition \\
\hline 9 & Pupils can absolutely do \\
7 & Pupils can mostly do \\
5 & Pupils can often do \\
3 & Pupils can somewhat do \\
1 & Neutral \\
$1 / 3$ & Pupils somewhat cannot do \\
$1 / 5$ & Pupils mostly cannot do \\
$1 / 7$ & Pupils significantly cannot do \\
$1 / 9$ & Pupils absolutely cannot do \\
\hline \hline
\end{tabular}

\section{A questionnaire of participation competence}

A questionnaire with six paired comparison items from four performance criteria items was constructed to determine the opinions of teachers. Then, their opinions were used to determine more important performance criteria item as pupils' competence. We used an intensity of importance (Table II) in the paired comparison.

The data that we collected were introduced to calculate the weight of importance of each item.

TABLE II: INTENSITY OF IMPORTANCE

\begin{tabular}{cl}
\hline \hline Intensity & \multicolumn{1}{c}{ Definition } \\
\hline 1 & Equal importance \\
3 & Somewhat more important \\
5 & Much more important \\
7 & Very much more important \\
9 & Absolutely more important \\
\hline \hline
\end{tabular}

\section{B. Implementation}

A total of 46 valid responses were collected on January 30, 2016 at "The Educational Forum Chiba" from in-service teachers. All of the 46 teachers were working in Chiba Prefecture, Japan.

\section{RESULT}

\section{A. Results of Communication Competence}

Table III lists the result of teachers' opinions in terms of the communication competencies of their pupils. A geometric mean of 1.0 indicates a neutral intensity between "can do" and "cannot do." The values of the geometric standard deviation are listed in parentheses. The means of seven items were higher than 1.0 (active area), and these items were recognized as being something that the pupils could somewhat do.

\begin{tabular}{cc}
\begin{tabular}{c} 
TABLE III: RECOGNITION ABOUT COMMUNICATION COMPETENCE \\
\hline \hline Item No.
\end{tabular} & $\begin{array}{c}\text { Geometric mean (geometric standard } \\
\text { deviation) }\end{array}$ \\
\hline C1 & $1.52(3.96)$ \\
C2 & $0.83(4.38)$ \\
C3 & $1.91(3.25)$ \\
C4 & $1.12(3.44)$ \\
C5 & $1.62(3.26)$ \\
C6 & $2.26(2.65)$ \\
C7 & $1.11(3.95)$ \\
C8 & $2.37(3.30)$ \\
C9 & $0.87(3.82)$ \\
C10 & $2.40(2.62)$ \\
\hline \hline
\end{tabular}

The result is depicted as a radar chart in Fig. 3. The colored inner circle with a value less than 1.0 represents the area of the inactive situation of "cannot do."

The calculated means and variances of the log-transformed data were introduced into further analysis. There were statistically significant differences between group means, as determined via one-way ANOVA $(\mathrm{F}(9,450)=4.92>\mathrm{p}=0.01)$.

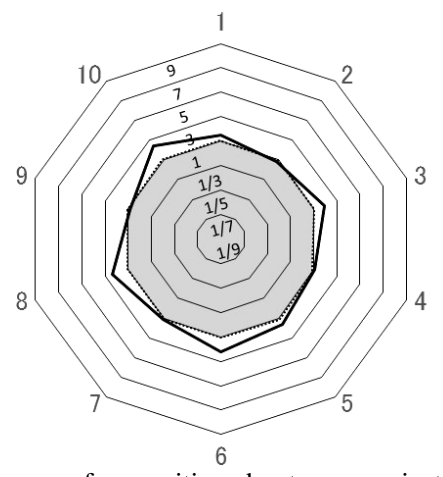

Fig. 3. Geometric mean of recognition about communication competence.

Then, we introduced the multiple-comparison (post-hoc test) using the Steel-Dwass test. This procedure compares the medians/means of all groups against a control using the Steel pairwise ranking nonparametric method.

$$
\begin{aligned}
\sqrt{2} \times \mathrm{t}_{\mathrm{C} 2, \mathrm{c} 6}=4.61>4.47=\mathrm{q}(10, \infty ; 0.05) \\
\sqrt{2} \times \mathrm{t}_{\mathrm{C} 2, \mathrm{c} 8}=4.86>4.47=\mathrm{q}(10, \infty ; 0.05) \\
\sqrt{2} \times \mathrm{t}_{\mathrm{c} 2, \mathrm{c} 10}=4.55>4.47=\mathrm{q}(10, \infty ; 0.05) \\
\sqrt{2} \times \mathrm{t}_{\mathrm{C} 6, \mathrm{c} 9}=4.78>4.47=\mathrm{q}(10, \infty ; 0.05) \\
\sqrt{2} \times \mathrm{t}_{\mathrm{c}, \mathrm{c} 9}=4.99>4.47=\mathrm{q}(10, \infty ; 0.05) \\
\sqrt{2} \times \mathrm{t}_{\mathrm{c}, \mathrm{C} 10}=4.97>4.47=\mathrm{q}(10, \infty ; 0.05)
\end{aligned}
$$

The teachers understood that experiences of using SNS (C6, C10) and the security knowledge of pupils (C8) were somewhat active, and they recognized that pupils have lower competencies in digital data operation skills (C2) and critic insights in SNS (C9). In summary, the pupils were shown to possess higher abilities in concrete experiences at using SNS, but they were underdeveloped in integrated skills to handle and utilize accessed information.

\section{B. Result of Participation Competence}

We investigated the opinions of teachers' recognition about importance of participation competence. The results of the paired comparison among the performance criteria items in participation competence (the details of the items are provided in Section II) are listed in Table IV.

TABLE IV: IMPORTANCE OF PARTICIPATION COMPETENCE

\begin{tabular}{lrrrrrr}
\hline & Involve & Risk & Interact & Tool & $\begin{array}{c}\text { Geometric } \\
\text { mean }\end{array}$ & $\%$ \\
\hline Involve & 1 & 0.40 & 0.88 & 1.42 & 0.841 & 19.2 \\
Risk & 2.49 & 1 & 2.55 & 2.81 & 2.056 & 47.0 \\
Interact & 1.14 & 0.39 & 1 & 1.85 & 0.953 & 21.8 \\
Tool & 0.70 & 0.36 & 0.54 & 1 & 0.607 & 13.9 \\
\hline \hline
\end{tabular}

We calculated the weight from the geometric mean of each line. Next, all of the geometric means were normalized and fixed to a percentage as the level of importance. The "risk" was selected as the highest score and weighted 47.0 percent of the importance. Teachers noted that approximately half of importance existed in "Aware of the consequences and risks of participating in SNS."

\section{Result of Monitoring Competence}

Table V lists the result of teachers' opinions in terms of the monitoring competencies of their pupils. 
TABLE V: RECOGNITION ABOUT MONITORING COMPETENCE

\begin{tabular}{cc}
\hline Item No. & $\begin{array}{c}\text { Geometric mean (geometric standard } \\
\text { deviation) }\end{array}$ \\
\hline M1 & $1.34(3.73)$ \\
M2 & $0.82(3.90)$ \\
M3 & $0.67(4.13)$ \\
M4 & $0.63(3.93)$ \\
M5 & $0.78(3.33)$ \\
M6 & $0.47(3.39)$ \\
M7 & $0.48(3.18)$ \\
M8 & $0.60(3.23)$ \\
M9 & $0.43(3.19)$ \\
M10 & $0.56(3.55)$ \\
M11 & $0.83(3.75)$ \\
\hline
\end{tabular}

This result is depicted as a radar chart in Fig. 4. The means of 10 items (i.e., all of the items except for M1) were shown to be lower than 1.0 (inactive area), and monitoring competence was recognized as something "pupils somewhat cannot do."

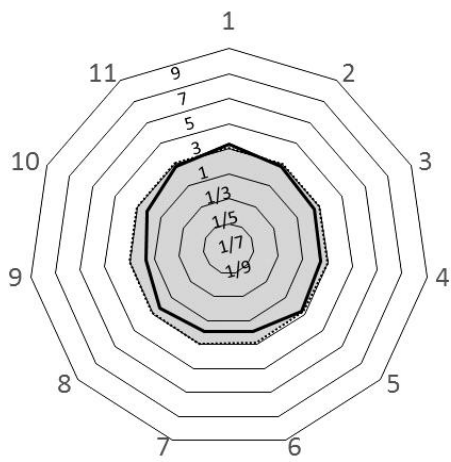

Fig. 4. Geometric mean of recognition about monitoring competency.

The calculated means and variances of the log-transformed data were introduced into further analysis. There were statistically significant differences between group means, as determined via one-way ANOVA $(\mathrm{F}(10,495)=3.04>\mathrm{p}=0.01)$.

Then, we also performed multiple comparisons using the Steel-Dwass test.

$$
\begin{aligned}
& \sqrt{2} \times \mathrm{t}_{\mathrm{M} 1, \mathrm{M} 6}=5.19>4.56=\mathrm{q}(11, \infty ; 0.05) \\
& \sqrt{2} \times \mathrm{t}_{\mathrm{M} 1, \mathrm{M} 7}=5.21>4.47=\mathrm{q}(11, \infty ; 0.05) \\
& \sqrt{2} \times \mathrm{t}_{\mathrm{M} 1, \mathrm{M} 9}=5.68>5.23=\mathrm{q}(11, \infty ; 0.01)
\end{aligned}
$$

The teachers understood that pupils knew how to use SNS (M1), but they also comprehended that the pupils did not know how to utilize the collected data (M6), how to monitor ownership of SNS (M7), or how to monitor public relation services and lobbyists (M9). In summary, the pupils were recognized as being underdeveloped in integrated skills to handle and utilize information; this result is similar to the result noted in terms of communication competence.

\section{DISCUSSION}

\section{A. Counter Risk Competencies}

As shown in Fig. 1, participation competence locates between communication competence and monitoring competence. Furthermore, the "risk" in participation competence was clearly recognized by teachers as being the most important item. However, the scores of the performance criteria items in communication competence regarding risk (C5, C6. C7, and C8) reflected active judgment. To sum up these results, teachers recognized pupils' risk ability as being active; nevertheless, teachers still felt importance in risk ability. It seems reasonable to conclude that teachers consider that the present threat of SNS to pupils is a serious problem.

On the other hand, unfortunately, there is no performance criteria item in terms of "risk" in monitoring competence. Integrated operation skills (M2, M5, M10, M11), contents aggregating (M6, M9), analysis (M4, M7), and decision-making (M3, M8) were more enhanced in monitoring competence. Furthermore, there is strong emphasis on democratic citizenship throughout the performance criteria items. Therefore, the performance criteria items of the UNESCO correspond poorly to Japanese schools.

In fact, enhancement of social media is consistent with the report of the UNESCO assessment framework in which considerations of pupils' risks and safety when using SNS is treated as being of little importance. The UNESCO deals with this threat of SNS in different areas of learning of safe and responsible use of ICT [12].

However, there are efforts underway to protect pupils from cybercrime in Japan. As a part of education, rules of using SNS, the ability to collect information, cyber morals, copyrights, and sympathy to others are planned [13]. The contents seem to be in confusion to design both SNS competencies and cyber safety in a same school lesson, and we need to have a candid discussion about the separation between enhancement and protectionism of SNS.

So far, we surveyed this discussion of introducing social media in education between empowerment and protectionism of world trends, and we concluded that it is beneficial to apply more weight in enhancement to give pupils the change to adapt to cyber society [14].

\section{B. SNS Types and Competencies}

An SNS allows people to join, own, and edit a personal profile page, to connect with online users, and to communicate with these users [15]. In terms of classifying SNS based on the style of cyber communication, Thelwall et al. proposed a typology of the following three types of SNS [16]:

1) Socializing SNS: Supporting informal social interactions between members (e.g., Facebook)

2) Networking SNS: Supporting non-social interpersonal communication, people-finding SNS (e.g., LinkedIn)

3) Navigation SNS: Supporting finding resources via interpersonal connections (e.g., YouTube)

The categories noted above include using SNS in one's personal spare time. In addition, these categories ask users to expand their human communication, especially in networking SNS.

Chatti was an initiator of the 'Learning as a Network' theory, which advocated the importance of network connections of learners [17]. This author explains that the result of learning is a restructuring of one's personal knowledge network, that is, an extension of one's external network with new knowledge nodes (external level) and a reframing of one's theories-in-use (conceptual/internal level). Therefore, SNS at this moment are not only recognized as a problematic social nuisance but also has an important role in developing a learner's knowledge. 
Fig. 5 shows the typology of SNS types. We mapped collected SNS sites into the framework based on the review data of familiar SNS of youth [10]. Unfortunately, there was no favorable SNS response for networking SNS, so the author adopted LinkedIn as the index.

We also mapped the scores of the performance criteria. The geometric means of related performance criteria items are shown in parentheses. Many performance criteria items were involved in this figure, and they ranged from active-level to inactive-level around navigation SNS and socializing SNS. However, there were no corresponding performance criteria items around networking SNS.

One aspect to note is that the UNESCO performance criteria items have low considerations to use networking SNS sites of non-social interpersonal SNS.

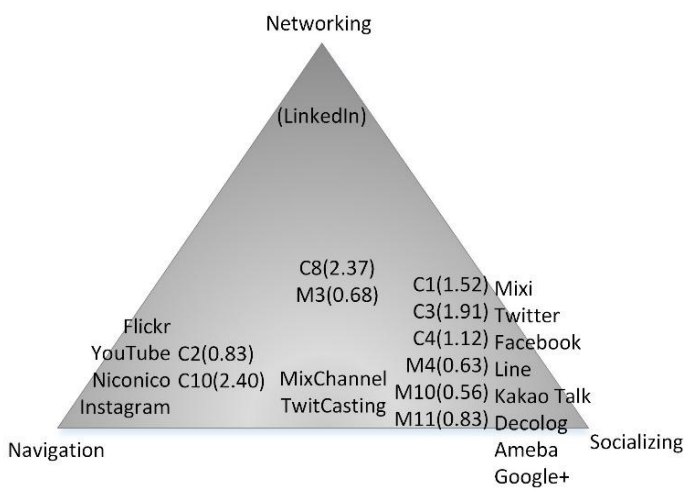

Fig. 5. Relation between performance criteria and typology triangle (C: communication, M: monitoring).

\section{SNS as Knowledge Building}

Networking SNS site requires the ability to develop human relations through SNS, but the UNESCO assessment framework makes more enhancement on information management through communication. Furthermore, the conceptual framework of the UNESCO includes democratic citizenship in which pupils should have good social skills, a democratic mind, and make contributions to good governance [18]. Additionally, related performance criteria items are seen in M2, M7, M8, and M9 and occupy a major fraction of monitoring competence.

Chatti advocated the following aspect about knowledge construction:

... everyone is a knowledge networker and can thus act as a novice in one context and step into the expert role in another context...

(Cited from [17])

The point is that there is an emerging view of competencies for a knowledge-based society to develop in SNS that places more focus on increasing connections among users than on collecting information.

The SNS as learning environment would lead to an argument about strengthening the future learning of pupils using SNS. Enhancement of a knowledge construction and democratic citizenship will not directly fall in line with the expansion of the personal learning environment, and measures to increase connections should be designed to enhance pupils' learning in networking-type SNS services.

As a feasible example, an SNS service in Japan, Studyplus, offer a place for students to communicate; this service has 1.6 million users [19]. Other educational SNS services have also appeared in cyberspace [20]. These services can develop new learning environments for pupils and introduce performance criteria items for reconsideration that take into account cyber threat problems.

\section{ACKNOWLEDGMENT}

The author would like to express special thanks to the Chiba Prefecture Teachers' Union and Rengo Chiba for the opportunity to carry out this questionnaire study.

\section{REFERENCES}

[1] Ministry of Internal Affairs and Communication. (June 15, 2013) Points of Survey for Information and Communication. [Online]. Available: http://goo.gl/QmzR4T

[2] MEXT, "Investigation on situation of information technology for education in schools," MEXT, Tokyo 2015.

[3] G. Siemens, Knowing Knowledge, Vancouver: Lulu Press, 2006.

[4] Cabinet office, Government of Japan, "Report of investigation on emvironment of using Internet by youth, 2013," Cabinet office, Government of Japan, Tokyo 2014

[5] National Institute for Educational Policy Research, "Results of national investigation of students' ability," National Institute for Educational Policy Research, Tokyo 2015.

[6] K. S. Young, Caught in the Net: How to Recognize the Signs of Internet Addiction-and a Winning Strategy for Recovery, John Wiley \& Sons, 1998.

[7] Japan Broadcasting Corporation. (March 7, 2014). Increasing Smartphone Troubles in Primary Students. [Online]. Available: http://goo.gl/JQ97PK

[8] A. Ougonzaki. (March 7, 2016). Rapidly Increasing Troubles of Highschools, and Use of SNS by Secondary Students Records Highest. [Online]. Available: http://goo.gl/JXWThA

[9] UNESCO Communication and Information Sector, "Glabal media and information literacy assessment framework. country readiness and competencies," Paris: France: UNESCO, 2013.

[10] Institute for Information and Communication Policy, "Report on the smartphone application use and net-dependent tendency of high schoo students," Institute for Information and Communication Policy, Tokyo 2014.

[11] T. L. Saaty, "Group decision making and the AHP," The Analytic Hierarchy Process, Springer, 1989, pp. 59-67.

[12] UNESCO Bangkok APEID-ICT in Education Team, Fostering digital citizenship through safe and responsible use of ICT, "A review of current status in Asia and the Pacific as of December 2014," Bangkok: UNESCO Bangkok, 2015.

[13] Tokyo Metropolitan Government. (March 18, 2016). Formulate Tokyo Rule for SNS. [Online]. Available: http://goo.gl/tYXXgT

[14] M. Yoshida, "Perspective views of empowerment and protectionism of in-service teachers about using social media in education," presented at the Sixth International e-Learning Conference 2015, Global Trends in Digital Learning, BITEC: Bangkok, 2015.

[15] N. B. Ellison, "Social network sites: Definition, history, and scholarship," Journal of Computer Mediated Communication, vol. 13, pp. 210-230, 2007

[16] M. Thelwall and D. Stuart, "Social network sites. An exploration of features and diversity," Social Computing and Virtual Communities, Boca Raton: CRC Press, 2009.

[17] M. A. Chatti. (October 14, 2013). The LaaN Theory. [Online] Available: http://goo.gl/6zb2jq

[18] A. Grizzle, P. Moore, M. Dezuanni, S. Asthana, C. Wilson, F. Banda et al., Media and Information Literacy: Policy and Strategy Guidelines, France: UNESCO, 2013.

[19] Studyplus, Inc. (May 25, 2016). Studyplus. [Online]. Available: http://info.studyplus.jp/

[20] TdTechReview, "100 popular web tools for teachers \& educators," New Delhi, India: EdTechReview, 2015, p. 23. 


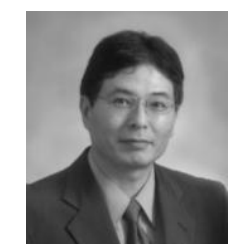

Masami Yoshida was born in Osaka, Japan in 1957. His major field is educational technology, and he has B.Sc. and M.Edu.

He used to work for Faculty of Education, Toyama University, and did studies regarding Educational Technology. Then, he moved to National Institute of Multimedia Education, and was involved in a project to study Faculty Development and Distance Education. He also had experiences to contribute to Japan International Cooperation Agencies (JICA) as a training expert in Thailand, Malaysia, and Papua New Guinea. Recently, he gave instruction to directors of educational TV in African, South American and Asian countries at JICA Okinawa training center. During 2014, he had a chance of a sabbatical leave, and had joint studies in Chulalongkorn University and Silpakorn University in Thailand.
As his social contribution activities, he is an executive member of All Japan Organization of Social Contribution (AJOSC) and Association of Educational Information for International Communication (AEIIC).

Now, he teaches at Faculty of Education and Graduate School of Education, Chiba University, and Graduate School of Social Sciences and Humanities, Chiba University. His recent publication is "Information Communication Technology and Changes of Education", In Novel Situation of Education. Chap. 15, The Center for Research and Development in Teacher Education, Faculty of Education, Chiba University (ed.), Tokyo: Hukumura Pub.

Prof. Yoshida is the member of the Japan Society for Educational Technology, Japan Association for Educational Media Society, Japan Society for Information and Systems in Education, and Japan Association for College and University Education. 